\title{
HUBUNGAN PERILAKU MEROKOK DENGAN PENGGUNAAN NAPZA JENIS AMPHETAMIN PADA MAHASISWA PERHOTELAN PERGURUAN TINGGI DI KOTA DENPASAR TAHUN 2019
}

\section{THE RELATIONSHIP OF SMOKING BEHAVIOR WITH THE USE OF AMPHETAMIN TYPE OF DRUGS IN HIGHER EDUCATION HOSPITALITY STUDENTS IN DENPASAR 2019}

\author{
Sri Idayani, Ni Luh Nova Dilisca Dwi Putri \\ Program Studi Teknologi Laboratorium Medis Program Diploma Tiga \\ STIKes Wira Medika Bali
}

\begin{abstract}
ABSTRAK
Salah satu faktor yang mempengaruh penyalahgunaan narkoba adalah kebiasaan merokok. Risiko terhadap penyalahgunaan narkoba cenderung meningkat pada seseorang yang memiliki kebiasaan merokok dan minum alkohol. NAPZA merupakan singkatan dari Narkotika, Psikotropika dan Bahan Adiktif berbahaya lainnya. Salah satu jenis NAPZA yaitu amphetamine. Amphetamine dapat berupa bubuk putih, kuning, maupun coklat, atau bubuk putih kristal kecil dan dapat juga berbentuk sediaan farmasi (tablet). Penelitian ini bertujuan untuk mengetahui hubungan antara perilaku merokok dengan penggunaan NAPZA jenis amphetamin dari urin mahasiswa perhotelan di Perguruan Tinggi Kota Denpasar Tahun 2019. Perilaku merokok dianalisa dari hasil wawancara menggunakan kuesioner dan kandungan amphetamine dari urin di uji dengan menggunakan metode rapid diagnostic test. Jumlah sampel yang urin yang dianalisa sebanyak 27 mahasiswa perhotelan Perguruan Tinggi di Kota Denpasar. Hasil penelitian menunjukkan, uji statistic Chi-Square diperoleh p-value tidak ada data statistik yang dihasilkan karena penggunanan NAPZA jenis amphetamine konstan. Hal tersebut berarti tidak ada hubungan antara perilaku merokok dengan penggunaan NAPZA jenis amphetamin pada urin mahasiswa perhotelan di Perguruan Tinggi Kota Denpasar Tahun 2019.
\end{abstract}

Kata Kunci: Perilaku Merokok, Amphetamin, Urin, Mahasiswa Perhotelan

\section{ABSTRACT}

One of the factors that influence drug abuse is smoking. The risk of drug abuse tends to increase in someone who has the habit of smoking and drinking alcohol. Some of the driugs are Narcotics, Psychotropic and other dangerous Addictive Materials. One of the drugs is amphetamine. Amphetamine can be white, yellow or cocoa powder, or small crystalline white powder and can also be in the form of pharmaceutical preparations (tablets). This study aims to determine the relationship between smoking behavior with the use of drug type amphetamines in the urine of hospitality students at Denpasar City University in 2019. Smoking behavior was analyzed from interviews using questionnaires and the 
Bali Medika Jurnal.

Vol 7 No 1, 2020: 138-145

ISSN : 2615-7047

DOI: https://doi.org/10.36376/bmj.v7i1

amphetamine content of urine was tested using the rapid diagnostic test method. The number of urine samples analyzed was 27 university hospitality students in the city of Denpasar. The results showed that the Chi-Square statistical test obtained p-value of no statistical data generated due to the use of constant type of amphetamine NAPZA. This means that there is no relationship between smoking behavior with the use of drug type amphetamines in the urine of hospitality students at Denpasar City University in 2019.

Keywords: Smoking Behavior, Amphetamine, Urine, Hospitality Students

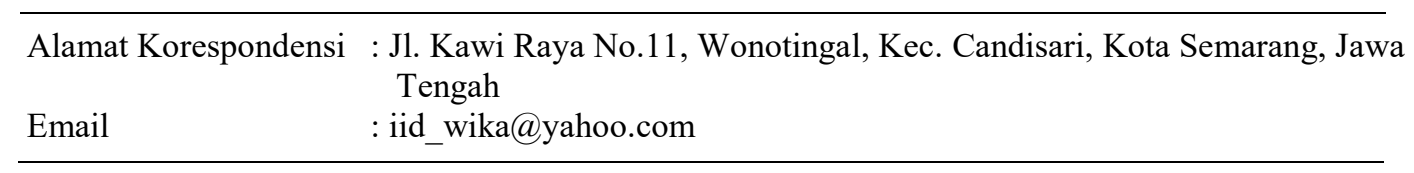

\section{PENDAHULUAN}

Penyalahgunaan narkoba di Indonesia, saat ini telah sampai pada tingkat mengkhawatirkan. Jumlah pengguna narkoba dari tahun ke tahun kian menunjukkan pengingkatan. Pemakai narkoba di Indonesia sudah lebih dari 2 juta orang. Jika hal ini dibiarkan, akan berakibat pada ancaman kelangsungan hidup manusia, sekaligus generasi berikutnya. Data yang diperoleh Badan Narkotika Nasional, jumlah remaja pengguna narkoba mengalami peningkatan. Tercatat peningkatan yang dialami mencapai angka rata-rata 15\% pertahun (BNN RI, 2014).

Pada sisi lain terdapat berbagai studi menunjukkan bahwa ada beberapa faktor yang mempengaruhi terjadinya penyalahgunaan narkoba. Salah satu faktor yang mempengaruh penyalahgunaan narkoba adalah kebiasaan merokok. Risiko terhadap penyalahgunaan narkoba cenderung meningkat pada seseorang yang memiliki kebiasaan merokok dan minum alkohol (Zhan et al., 2012). Penelitian di Indonesia dengan menggunakan data survei nasional penyalahgunaan dan pereadaraan gelap narkoba di tingkat rumah tangga Indonesia tahun 2005 (BNN RI \& Puslitkes UI, 2011) menunjukkan bahwa penduduk yang merokok mempunyai risiko 3,89 kali dalam penyalahgunaan narkoba jika dibandingkan dengan penduduk yang tidak merokok (Ismail, 2006).

Menurut BNN RI \& Puslitkes UI (2011), menunjukkan bahwa berdasarkan hasil analisis deskriptif terhadap tiga survei nasional perkembangan penyalahgunaan dan peredaraan gelap narkoba pada kelompok pelajar/mahasiswa di Indonesia selama tiga kali berturut-turut yaitu tahun 2006 dan 2009 sebesar 19\% perokok dan 2011 sebesar 20\% perokok. Secara khusus, angka merokok pada pelajar/mahasiswa yang menyalahgunakan narkoba dari ketiga survei yaitu tahun 2006 sebanyak 69\%, tahun 2009 sebanyak 62\%, dan tahun 2011 sebanyak 52\% (BNN RI \& Puslitkes UI, 2011). Sedangkan angka merokok pada pelajar/mahasiswa yang bukan penyalahguna narkoba hampir tidak ada perbedaan di antara tiga survei tersebut, yaitu $16 \%-17 \%$. Dari ketiga survei tersebut menunjukkan bahwa pelajar/mahasiswa yang melakukan penyalahgunaan narkoba tiga sampai empat kali lebih banyak pada mereka yang merokok dibandingkan dengan bukan penyalahguna narkoba (BNN RI \& Puslitkes UI, 2011). Sedangkan laporan dari National Center on Addiction and Substance Abuse menyebutkan bahwa 57\% remaja yang menyalahgunakan narkoba jenis ganja terlebih dahulu merokok (Rose, 2006). Studi tersebut juga menemukan bahwa remaja yang 
memiliki kebiasaan merokok 14 kali berisiko untuk menghisap narkoba jenis ganja dibandingkan dengan remaja yang tidak pernah merokok. Hasil itu juga dikuatkan oleh studi lain yang menunjukkan adanya kebiasaan merokok dengan menghisap narkoba jenis ganja pada remaja (Rose, 2006). Penelitian lain dengan menggunakan sampel remaja-remaja yang berdominisi di kota metropolitan Perancis juga menjelaskan hubungan antara kebiasaan merokok dengan penyalahgunaan nakroba jenis ganja (Mayet et al., 2011).

Departemen Kesehatan RI melaporkan bahwa salah satu daerah yang rentan peredaran narkoba itu adalah Pulau Bali. Daerah yang terkenal dengan pariwisata. Terlebih karena daerah itu menjadi tempat tujuan para turis mancanegara untuk berlibur. Pada perkembangannya Bali menjadi daerah yang terbuka bagi transaksi dan peredaran berbagai jenis narkoba. Bali memiliki 8 daerah Kabupaten dan 1 Kota. Salah satu daerah yang tidak luput dari peredaran gelap narkoba adalah Denpasar (BNN RI, 2010).

NAPZA merupakan singkatan dari Narkotika, Psikotropika dan Bahan Adiktif berbahaya lainnya, yaitu bahan atau zat yang jika dimasukkan dalam tubuh manusia, baik diminum, dihirup maupun disuntikkan yang mampu mengubah pikiran, perasaan dan juga perilaku seseorang dan lebih jauh lagi narkoba akan dapat menimbulkan ketergantungan fisik dan psikologis. Penyalahgunaan Narkotika merupakan salah satu masalah pemerintah yang perlu mendapatkan perhatian serius dari semua pihak. Hal ini dibuktikan dengan semakin meningkatkan kasus narkotika yang dilaporkan oleh berbagai media. Pada hal pemeriksaan jenis narkotika ini perlu dicari metode yang cukup teruji yang dapat menganalisa Narkotika tersebut dengan hasil yang optimal. Narkotika dalam senyawa metabolit akan terdeteksi dalam urine setelah 24 jam setelah pemakaian oleh pemakai, darah selama 3 x 24 jam setelah pemakaian, dan rambut setelah $4 \mathrm{x}$ 24 jam setelah pemakaian (Taufik et al., 2017).

Narkoba dibedakan ke dalam beberapa golongan yaitu sebagai berikut Narkotika golongan I: Narkotika yang hanya digunakan untuk ilmu pengetahuan dan tidak digunakan untuk tujuan pengobatan karena mempunyai potensi yang sangat kuat menimbulkan ketergantungan, contoh : heroin, ganja, dan kokain. Golongan II: narkotika yang berkhasiat untuk pengobatan digunakan sebagai pilihan terakhir dan dapat digunakan dalam terapi dan bertujuan sebagai pengembangan ilmu pengetahuan serta mempunyai potensi tinggi mangakibatkan ketergantungan, misalnya adalah morfin, petidin, turunan/garam narkotika dalam golongan tersebut dan lain-lain. Golongan III: narkoba yang berkhasiat pengobatan dan banyak digunakan dalam terapi dan bertujuan untuk pengembangan ilmu pengetahuan serta mempunyai potensi ringan mengakibatkan ketergantungan, misalnya adalah kodein, garam-garam narkotika dalam golongan tersebut dan lainlain (Lestari, 2013).

Penelitian yang dilakukan (Hariaji, 2017) terhadap 4880 sampel urin, menunjukkan bahwa terdapat 12 sampel urin yang positif mengandung THC, 33 sampel urin positif mengadung Methamphetamine dan terdapat pula 3 sampel urin yang positif mengandung THC dan Methamphetamine. Data yang didapatkan menunjukan bahwa terdapat penggunaan narkotika golongan Met dan THC di kalangan usia pra kuliah di kota Medan dan sekitarnya (Hariaji, 2017).

Amphetamine adalah obat golongan stimulansia Amphetamin, Methamphetamin, Metilendioksimetamfetamin (MDMA, ecstasy atau Adam). , 
awalnya digunakan secara terapetik untuk mengatasi obesitas, attention-deficit hyperactivity disorder (ADHD), narkolepsi, dan kelelahan kronis. Pada awalnya, amfetamin sangat populer digunakan untuk mengurangi nafsu makan dan mengontrol berat badan. Obat ini juga digunakan secara ilegal sebagai obat untuk kesenangan (Recreational Club Drug) dan sebagai peningkat penampilan (menambah percaya diri atau PD). Amphetamine dapat berupa bubuk putih, kuning, maupun coklat, atau bubuk putih kristal kecil dan dapat juga berbentuk sediaan farmasi (tablet) (Zulkarnain, 2016).

Efek penggunaan amphetamin dengan rokok akan bereaksi lebih cepat dibandingkan secara oral atau hirup. Pemberian secara oral atau hirup menimbulkan efek yang lebih lambat dan diserap di dalam tubuh lebih lambat. Waktu paruh amphetamin mencapai 8-13 jam dan adapun bahaya dari penggunaan amphetamine yaitu membuat pengguna amphetamine mengalami kerusakan hati, ginjal, paru-paru, otak yang menyebabkan terjadinya stroke atau epilepsi (Zulkarnain, 2016).

Untuk mengetahui kandungan amphetamin di dalam tubuh manusia akan terdeteksi dalam urine setelah 24 jam setelah pemakaian oleh pemakai. Telah banyak metode yang digunakan dalam pemeriksaan kandungan amphetamine yaitu teknik Immunoassay menggunakan metode rapid diagnostic test dan teknik Kromatografi Lapis Tipis (KLT) (Moeller et al., 2008).

Perguruan Tinggi Pariwisata rentan penyalahgunaan narkoba. Hal ini dibuktikan dengan ditemukannya kasus penyalahgunaan narkoba oleh mahasiswa bidang pariwisata disalah satu perguruan tinggi pariwisata salah satu yang berada di Kabupaten Singaraja.Ancaman bahaya penyalahgunaan narkoba sudah memasuki kondisi darurat, khususnya usia remaja yang sebagian besar dari kalangan pelajar dan mahasiswa. Menyikapi hal tersebut, jajaran Polres Buleleng manfaatkan masa pengenalan lingkungan sekolah pada tahun ajaran 2017/2018 ini untuk mensosialisaikan bahaya penyalahgunaan narkotika (Sundari, 2017).

Menurut Data Pengungkapan kasus Narkotika tahun 2005 sampai 2010, pengungkapan kasus narkotika yang paling banyak adalah Polresta Denpasar disetiap tahunnya dibandingkan dengan Kabupaten lainnya.pada tahun 2010, kasus penyalahgunaan dan peredaran gelap narkotika mencapai $18,35 \%$ dari total keseluruhan kasus. Denpasar kini telah menjadi kawasan paling rawan untuk peredaran narkoba, dengan kata lain Denpasar telah menjadi gudang Narkoba (BNN RI, 2010).

Berdasarkan uraian diatas, maka pada kesempatan ini peneliti ingin melakukan penelitian mengenai hubungan perilaku merokok dengan penggunaan NAPZA jenis amphetamin pada mahasiswa perhotelan di Perguruan Tinggi Kota Denpasar Tahun 2019 dengan menggunakan metode Rapid Test untuk screening dan mendeteksi kandungan amphetamine pada sampel urine.

\section{METODE PENELITIAN}

Pada penelitian ini akan dilakukan pemeriksaan kandungan amphetamin dalam urin mahasiswa perhotelan Perguruan Tinggi di Kota Denpasar. Teknik Immunoassay merupakan teknik umum yang digunakan untuk menganalisis obat terlarang. Penelitian teknik ini sangat tergantung pada beban kerja (jumlah sampel 
per-hari) selain mudah dilakukan teknik ini tidak membutuhkan biaya yang besar, akan tetapi hasil dari teknik ini hanya dapat dijadikan sebagai bahan pertimbangan, bukan untuk menarik kesimpulan, karena hasilnya dapat berupa positif palsu, yang mungkin dihasilkan karena terjadinya reaksi dengan berbagai senyawa yang ada baik bentuk struktur molekul maupun bangun yang hampir menyerupai. Pada rapid diagnostic test ini terdapat 2 zona yaitu, zona test dan zona kontrol. Dalam zona kontrol hanya terdapat 1 kandungan yaitu anti amphetamin. Zona kontrol ini merupakan zona untuk menentukan valid atau tidaknya strip test yang akan digunakan (Moeller et al., 2008).

Pengambilan sampel pada penelitian ini dilakukan di Perguruan Tinggi Kota Denpasar pada bulan Juli-Desember 2019. Jenis penelitian yang digunakan pada penelitian ini adalah penelitian deskriptif korelatif dengan pendekatan cross sectional study yang bertujuan untuk mengetahui hubungan perilaku merokok dengan penggunaan NAPZA jenis amphetamin Mahasiswa Perhotelan di Perguruan Tinggi Kota Denpasar. Selanjutnya penelitian akan dilanjutkan dengan uji laboratorium pada urin mahasiswa untuk mengetahui kandungan NAPZA jenis amphetamine. Populasi pada penelitian ini adalah seluruh mahasiswa perguruan tinggi di Kota Denpasar di semester akhir yang akan disalurkan ke Kapal Pesiar sebanyak 30 mahasiswa. Sampel urin yang diambil masing-masing sebanyak $5 \mathrm{~mL}$. Sampel pada penelitian ini adalah mahasiswa Perguruan Tinggi di Kota Denpasar semester akhir yang akan disalurkan ke Kapal Pesiar sebanyak 27 mahasiswa. Penentuan informan dilakukan dengan menggunakan teknik purposive sampling yang memenuhi kriteria inklusi. Teknik pengambilan sampel adalah purposive sampling yang memenuhi kriteria inklusi. Purposive sampling adalah Pengambilan sampel berdasarkan atas suatu pertimbangan tertentu seperti sifat-sifat populasi ataupun ciri yang sudah diketahui sebelumnya (Notoatmodjo, 2010). Jenis data yang digunakan pada penelitian ini adalah data primer yang diperoleh melalui wawancara dengan menggunakan kuesioner sebagai alat untuk wawancara untuk mengetahui perilaku merokok. Selain itu pengukuran kandungan amphetamine pada urin mahasiwa di Perguruan Tinggi Kota Denpasar dilakukan dengan menggunakan metode Rapid Diagnostic Test (RDT).

Pada penelitian ini data kuesioner dari hasil wawancara dan kandungan amphetamin pada urin mahasiswa perhotelan yang terbaca oleh strip test dianalisa menggunakan uji statistic Chi-Square kemudian interpretasikan secara deskriptif.

HASIL PENELITIAN

\section{HASIL DAN PEMBAHASAN}

Berdasarkan Hasil Analisis dapat dilihat pada Tabel berikut ini.

Tabel 1. Frekuensi Distribusi Responden Berdasarkan Perilaku Merokok

\begin{tabular}{ccc}
\hline Perilaku Merokok & Frekuensi & Prosentase \\
\hline Ringan & 22 & 81,5 \\
Berat & 5 & 18,5 \\
\hline Jumlah & 27 & 100,0 \\
\hline
\end{tabular}

Sumber: Hasil Penelitian 2019 (Data Diolah) 
Bali Medika Jurnal.

Vol 7 No 1, 2020: 138-145

ISSN : 2615-7047

DOI: https://doi.org/10.36376/bmj.v7i1

Tabel 2. Frekuensi Distribusi Responden Berdasarkan Penggunaan NAPZA Jenis Amphetamin

\begin{tabular}{ccc}
\hline $\begin{array}{c}\text { Penggunaan NAPZA } \\
\text { Jenis Amphetamin }\end{array}$ & Frekuensi & Prosentase \\
\hline Iya & 0 & 0 \\
Tidak & 27 & 100 \\
\hline Jumlah & 27 & 100,0 \\
\hline
\end{tabular}

Sumber: Hasil Penelitian 2019 (Data Diolah)

Tabel 3. Hubungan Perilaku Merokok dengan Penggunaan Napza Jenis Amphetamin Pada Mahasiswa Perhotelan

\begin{tabular}{|c|c|c|c|c|c|c|c|c|}
\hline \multirow{3}{*}{$\begin{array}{l}\text { Perilaku } \\
\text { Merokok }\end{array}$} & \multicolumn{4}{|c|}{$\begin{array}{l}\text { Penggunaan NAPZA } \\
\text { Jenis Amphetamin }\end{array}$} & \multirow{2}{*}{\multicolumn{2}{|c|}{ Total }} & \multirow[t]{3}{*}{$\mathrm{a}$} & \multirow[t]{3}{*}{ p-value } \\
\hline & \multicolumn{2}{|c|}{ Tidak } & \multicolumn{2}{|c|}{ Iya } & & & & \\
\hline & $f$ & $\%$ & $\mathrm{f}$ & $\%$ & $\mathrm{~F}$ & $\%$ & & \\
\hline Ringan & 22 & $100 \%$ & 0 & $0 \%$ & 22 & $100 \%$ & \multirow[b]{3}{*}{0.05} & \multirow{3}{*}{$\begin{array}{l}\text { Tidak ada data statistik } \\
\text { yang dihasilkan karena } \\
\text { penggunanan NAPZA } \\
\text { jenis amphetamine } \\
\text { konstan. }\end{array}$} \\
\hline Berat & 5 & $100 \%$ & 0 & $0 \%$ & 5 & $100 \%$ & & \\
\hline Total & 27 & $100 \%$ & 0 & & 27 & $100 \%$ & & \\
\hline
\end{tabular}

Sumber: Hasil Penelitian 2019 (Data Diolah)

\section{PEMBAHASAN HASIL}

Berdasarkan hasil penelitian menunjukkan bahwa perilaku merokok pada mahasiswa perhotelan di Perguruan Tinggi Kota Denpasar berada pada kategori ringan sebanyak $\quad 22(81,5 \%)$ responden. Sehingga tidak ada data statistik yang dihasilkan karena penggunanan NAPZA jenis amphetamine konstan. Hasil pemeriksaan terhadap 27 urin mahasiswa menunjukkan bahwa keseluruhan responden memberikan hasil negatif (tidak mengandung amphetamin) yang di tandai dengan terdapatnya 2 garis merah pada bagian kontrol dan test. Hal tersebut karena pengetahuan responden baik terkait penyalahgunaan NAPZA bagi kesehatan.

Hasil penelitian ini tidak sejalan dengan penelitian Astuti (2016) tentang "Merokok Pintu Masuk Untuk Penyalahgunaan Narkoba Jenis Ganja" menunjukkan bahwa terdapat hubungan kuat antara penyalahgunaan narkoba jenis ganja dengan kebiasaan merokok. Oleh karena itu bukan hanya persoalan narkoba yang perlu perhatian pada upaya pencegahan dan penanggulangan, akan tetapi persoalan kebiasaan merokok khususnya dikalangan anak-anak, pelajar/mahasiswa juga harus menjadi perhatian yang serius.

Menurut penelitian Rambe (2017) tentang" Analisa Narkoba Jenis Morfin, Amfetamin Dan Thc(Tetrahidrokannabinol) Menggunakan Strip Test" menjelaskan bahwa metode yang digunakan dalam pemeriksaan narkoba yaitu Immunochromatografi Kompetitif, strip dicelupkan secara vertikal pada spesimen urine lalu ditunggu beberapa menit dan dilihat hasilnya, jika tertera garis pada kontrol dan test menunjukkan negatif, jika tertera garis pada kontrol menunjukkan positif sedangkan jika tidak tertera garis menunjukkan invalid. Sehingga diperoleh hasil bahwa sampel urine yang diuji menunjukkan hasil positif berarti pasien 
merupakan pengguna narkoba. Hasil analisa diperoleh hasil negatif pada satu sampel urine dan hasil positif pada dua sampel urine yang mengandung amfetamin dan tetrahidrokannabinol.

Penyalahgunaan narkoba oleh remaja merupakan masalah yang serius, karena penyalahgunaan narkoba dapat merusak masa depan remaja. Generasi muda merupakan sasaran strategis bagi mafia perdagangan narkoba. Oleh karena itu, bukan hanya persoalan narkoba yang perlu perhatian tetapi pada upaya pencegahan dan penanggulangan kebiasaan merokok, khususnya di kalangan anak-anak, pelajar/mahasiswa. Berbagai pihak, seperti pemerintah, Lembaga Swadaya Masyarakat, masyarakat umum, termasuk juga pihak sekolah dan perguruan tinggi harus bergerak untuk melakukan hal tersebut. Apabila persoalan kebiasaan merokok tidak ditangani secara sungguh-sungguh, maka pada masa yang akan datang bisa memberikan dampak terhadap peningkatan penyalahgunaan narkoba.

\section{SIMPULAN DAN SARAN}

Berdasarkan hasil penelitian maka dapat ditarik kesimpulan yaitu, tidak ada hubungan antara perilaku merokok dengan penggunaan NAPZA jenis amphetamine pada mahasiswa perhotelan di Perguruan Tinggi Kota Denpasar Tahun 2019. Saran pada penelitian ini adalah untuk pihak perguruan tinggi di Kota Denpasar agar tetap memberikan informasi tentang bahaya dan upaya menghindari penggunaan rokok dan narkoba kepada mahasiswa baik melalui forum-forum pertemuan maupun himbauan media promosi di sekitar kampus. Mahasiswa perguruan tinggi di Kota Denpasar agar tetap memiliki konsep tentang nilai baik dan tetap menjauhkan diri dari pemakaian rokok dan narkoba.

\section{UCAPAN TERIMA KASIH}

Dengan segala hormat dan kerendahan hati, penulis menyampaikan penghargaan dan terimakasih yang sebesar-besarnya kepada:

1. Ketua dan para Wakil Ketua STIKes Wira Medika Bali yang mendorong penulis untuk melakukan dan melaksanakan penelitian ini agar dapat dipergunakan sebagai referensi dalam pengembangan, pemanfaatan dan penerapan ilmu analis kesehatan dalam bidang toksikologi klinik.

2. Seluruh civitas akademika STIKes Wira Medika Bali yang telah banyak membantu penulis dalam menyelesaikan penelitian ini.

3. Seluruh rekan-rekan dosen dan semua pihak yang tidak dapat disebutkan satu persatu yang telah banyak membantu dalam pembuatan penelitian ini.

\section{DAFTAR PUSTAKA}

Astuti, N. H. (2016). Merokok Pintu Masuk untuk Penyalahgunaan Narkoba Jenis Ganja. ARKESMAS (Arsip Kesehatan Masyarakat), 1(1).

BNN RI. (2010). Hasil Studi Penyalahgunaan Narkoba di Kalangan Pekerja di Indonesia Tahun 2009. Badan Narkotika Nasional Republik Indonesia. 
https://bnn.go.id/studi-penyalahgunaan-narkoba-di-kalangan-pekerja-diindonesia/

BNN RI. (2014). Psikotropika. Badan Narkotika Nasional Republik Indonesia. http://bnn.go.id

BNN RI, \& Puslitkes UI. (2011). Survei Nasional Perkembangan Penyalahgunaan Dan Peredaran Gelap Narkoba Pada Kelompok Pelajar / Mahasiswa Di Indonesia Tahun 2011.

Hariaji, I. (2017). Gambaran Penyalahgunaan Tetrahidrocannabinol (THC) dan Metamphetamine (Met) Pada Usia Pra Kuliah di Kota Medan Dan Sekitarnya Tahun 2016. Buletin Farmatera, 2(1), 9-15.

Ismail, A. (2006). Hubungan Riwayat Merokok dengan Penyalahgunaan Narkoba di Indonesia (Analisis Data Survei Nasional Penyalahgunaan dan Peredaran Gelap Narkoba pada Rumah Tangga di Indonesia Tahun 2005). Universitas Indonesia.

Lestari, S. I. (2013). Strategi Badan Narkotika Nasional Kota Samarinda dalam menanggulangi penggunaan narkoba di Kelurahan Sungai Pinang Dalam Kota Samarinda. Ejournal Ilmu Pemerintahan, 1(2), 943-955.

Mayet, A., Legleye, S., Chau, N., \& Falissard, B. (2011). Transitions Between Tobacco and Cannabis Use Among Adolescents: A Multi-state Modeling of Progression from Onset to Daily Use. Addictive Behaviors, 36(11), 11011105. https://doi.org/10.1016/j.addbeh.2011.06.009

Moeller, K. E., Lee, K. C., \& Kissack, J. C. (2008). Urine Drug Screening: Practical guide for Clinicians. Mayo Clinic Proceedings, 83(1), 66-76. https://doi.org/10.4065/83.1.66

Notoatmodjo, S. (2010). Ilmu Perilaku Kesehatan. Rineka Cipta.

Rambe, E. S. D. (2017). Analisa Narkoba Jenis Morfin, Amfetamin Dan The (Tetrahidrokannabinol) Menggunakan Strip Test. Jurnal Departemen Kimia Universitas Sumatera Utara.

Rose, J. D. (2006). The Relationship Between Tobacco, Alcohol, Marijuana Use Among Teenagers. In Electronic Theses and Dissertations (p. Paper 2171). https://dc.etsu.edu/etd/2171/

Sundari, A. (2017). Mahasiswa Bidang Pariwisata Rentan Penyalahgunaan Narkoba. Radio Republik Indonesia.

Taufik, M., Marpaung, H., Gultom, J., \& Raja, S. L. (2017). Pemeriksaan Narkotika Menggunakan Sampel Urine. Jurnal Stikna, 1(1), 1-10.

Zhan, W., Dierker, L. C., Rose, J. S., Selya, A., \& Mermelstein, R. J. (2012). The Natural Course of Nicotine Dependence Symptoms Among Adolescent Smokers. Nicotine and Tobacco Research, 14(12), 1445-1452. https://doi.org/10.1093/ntr/nts031

Zulkarnain, Z. (2016). Penyalahgunaan Narkoba dalam Perspektif Hukum Islam dan Hukum Positif Indonesia. Universitas Islam Negeri Sumatera Utara. 